\title{
Anti-Metastatic Drug Developments: Work Out towards New Direction
}

Da-Yong Lu' ${ }^{1 *}$, Ting-Ren $\mathrm{Lu}^{1}$, Bin $\mathrm{Xu}^{2}$, Jin-Yu Che' ${ }^{1}$, Shu-Yun $\mathrm{Wu}^{2}$, Hong-Ying $\mathrm{Wu}^{1}$ and Nagendra Sastry Yarla ${ }^{3}$

${ }^{1}$ Shanghai University, Shanghai 200444, PRC

${ }^{2}$ Shanghai Institute of Materia Medica, Chinese Academy of Sciences, Shanghai 201203, PRC

${ }^{3}$ Divisions of Biochemistry and Chemistry, City University of New York School of Medicine, 160 Convent Avenue, New York, NY 10031, USA

\begin{abstract}
Neoplasm metastasis is a multiple-step and multi-level feature that is resistance to current norm of anticancer drugs. More seriously, current anticancer drugs are commonly derived from in vitro tumor cell line data or animal models of primary tumors rather than workable metastatic models reflecting clinical situations. This article provides different aspects of pathologic/pharmacological information and study against neoplasm metastasis.
\end{abstract}

Keywords: Neoplasm metastases; Cancer chemotherapy; Cancer plasticity; Drug combination; Clinical cancer trial; Metastatic cascade; Cancer stem cells; Personalized medicine

\section{Background}

\section{Medical significance}

Neoplasm metastasis is a multiple-step and high plasticity phenotype that is resistance to current conventions of drug therapeutics. Previously, chemotherapeutic benefits against cancer growths and metastasis were usually derived from experimental models and data of in vitro tumor cell lines and volume of primary tumors. Accordingly, antimetastatic drugs (several types available) are often used as assistant agents to cancer therapy.

\section{Problem origination}

Generally speaking, cancer patient's survival has hardly been improved in patients with overt metastasis (late-pathologic stage) from current therapeutic conventions and shortage of antimetastatic drugs in the clinic [1]. Therefore, any small breakthrough for drug developments in this area will achieve therapeutic benefits in clinical cancer trials [29]. In order to achieve this goal, the patho-therapeutic relationship must be analyzed by literature survey, our past experimental data and existing biological theories.

\section{Current Therapeutics Against Neoplasm Metastasis}

\section{Therapeutic mechanisms of current antimetastatic drugs}

Antimetastatic drugs have been developed over half a century worldwide $[10,11]$. The therapeutic targets under investigations are approximately ten categories (Table 1). We will discuss them in details next sectors.

\section{Detail Information of Antimetastatic Drugs}

\section{Bisdioxopiperazine compounds}

Bisdioxopiperazine compounds (Biz), including ICRF-154, Razoxane (ICRF-159, Raz), ICRF-186 and ICRF-187 (two stereoisomers of Raz) and ICRF-193, developed in the UK, have been a series of serendipitous agents found to be significantly effective against a model of spontaneous metastasis (Lewis lung carcinoma, 3LL) [11,12]. Ever since their development (1969), new analogs Probimane and Bimolane were synthesized at the Shanghai Institute of Materia Medica, Chinese Academy of Sciences, Shanghai, China [35,36]. Early mechanistic studies of Biz compounds were reported in China and UK [37-39].

\section{MMP inhibitors (tumor matrix)}

Primary tumors are embedded in surrounding matrix. Tumor cells and their surrounding matrix can secrete a spectrum of proteinases that can break up these surrounding matrixes and make tumor cells penetrable through these surrounding matrixes and finally intrigue invasion-metastasis cascade. These proteinases are composed of matrix metalloproteinase (MMPs). MMPs inhibitors are those agents proposed to inhibit tumor metastases in early metastaticstage [13].

\section{Angiogenesis inhibitors}

Metastatic cells, after extravasation to remote organs, need newblood vessels to offer nutrients to transform the dormant/micrometastatic tumor to metastatic outgrowth (overt metastatic colony) in distant tissues. Drugs (commonly antibody against these series of vascular factors/promoters) are generally known as anti-vascular anticancer drugs $[14,15,40,41]$. However, several weeks/months survival benefits are far from our requirement of long-term disease control ( $>5$ years) or even cure patients with neoplasm metastasis.

\section{Bisphosphonates (BP) in the treatment of osteolytic metastases}

BP has a long history of being used in treating osteoporosis. It was already licensed to treat osteolytic metastasis. Others suggest that BP can influence from oncogenes to metastatic-related genes in treating metastases of many organs.

\section{Immune system promoters (Plant extracts or chemicals)}

Treatment of neoplasm metastases by plant extracts or chemicals seems to be a future trend. Now, growing numbers of plant extracts, chemicals and alkaloids have been found to inhibit tumor metastases in animal models [16]. These polysaccharides are proposed to enhance immune response in animals and humans.

*Corresponding author: Da-Yong Lu, Shanghai University, Shanghai 200444 People's Republic of China (PRC), Tel: +862166163545; E-mail: ludayong@shu.edu.cn

Received July 23, 2018; Accepted July 26, 2018; Published July 31, 2018

Citation: Lu DY, Lu TR, Xu B, Che JY, Wu SY, et al. (2018) Anti-Metastatic Drug Developments: Work Out towards New Direction. Med Chem (Los Angeles) 8: $192-$ 196. doi: 10.4172/2161-0444.1000512

Copyright: ( 2018 Lu DY, et al. This is an open-access article distributed under the terms of the Creative Commons Attribution License, which permits unrestricted use, distribution, and reproduction in any medium, provided the original author and source are credited. 
Citation: Lu DY, Lu TR, Xu B, Che JY, Wu SY, et al. (2018) Anti-Metastatic Drug Developments: Work Out towards New Direction. Med Chem (Los Angeles) 8: 192-196. doi: 10.4172/2161-0444.1000512

\begin{tabular}{|c|c|c|}
\hline Drug categories & Involving molecules \& pathways & References \\
\hline Bisdioxopiperazine compounds & Tumor cell detachments & {$[10,11]$} \\
\hline MMP inhibitors & Tumor stroma (extracellular matrix, ECM) & [12] \\
\hline Angiogenesis inhibitors & Tumor blood \& nutrition & {$[13,14]$} \\
\hline Bisphosphonates & Bone metastasis & {$[15]$} \\
\hline Various drugs & Invasion-metastasis cascade & {$[16,17]$} \\
\hline Probimane \& polysaccharide & Aberrant sialylation in tumors & [18-22] \\
\hline Immune promoters & Tumor cells/cluster in vasculatures & {$[23,24]$} \\
\hline Assistant therapy & Blood coagulants & [25-27] \\
\hline Cancer stem cell inhibitors & Difficult to define currently & [28-30] \\
\hline Next generation & Seed and soil & [24] \\
\hline New generation & Cancer plasticity state & [31-33] \\
\hline Traditional Chinese medicine & Human body and organ functionality & [34] \\
\hline
\end{tabular}

Table 1: The evolution of anti-metastatic targets and drugs.

\section{Invasive-metastasis cascade}

Present antimetastatic therapy treats patients equally. No specific attentions are paid according to clinical situations of patients.

From this pathologic point of view, since a metastasis must travel more than one body-organ, the obvious different anatomic organs may possibly trigger different molecules and pathways linking neoplasm metastases. This reasonably results in being affected or inhibited with different types of drugs in different stages of metastatic processes [17].

In general, it was proposed that the MMPs inhibitors might be more active in preventing tumor cells from detaching primary locations [13]. Immuno-modulators might promote the activity of macrophages in killing tumor cells during the vascular and lymphatic circulations [16]. Angiogenesis inhibitors might be used as the substage of attaching of tumor cells to metastatic outgrowth to distant organs. However, highly cytotoxicity agents might be more effective in the treatment of formed metastatic colony and preference-organs [42-45] (Figure 1).

\section{Circulating tumor cells and clusters for drug targets}

In invasive-metastatic cascade, tumor cells/clusters must circulate in human blood or lymphatic vessels seeking refuge in distant organs [33].

The neoplasm metastasis is a mechanically dynamic process in human body. Tumor cells/cluster circulating in vascular system (blood or lymphatic) is one of the most noticeable one. In the past, it has been found that tumor cells in vascular systems have higher ratio of mesenchymal state that can be cleared by human immune systems. It is found that agents of immune promotion can reduce the number of tumor cells/clusters floating in human vasculature. The circulating tumor cells (mesenchymal type-rich) in human vasculatures are a different one comparing with in primary/metastatic colony (epithelial type-rich) in human body [32-34]. As a result, this is an interesting drug targets for metastatic control and managements. Certainly, it should not be restricted in drug type of immune system promotions.

\section{Tumor stroma and assistant therapy}

Cell adhesion molecules (CAM), such as E-cadherin, p-cadherin, integrin, selectin, play key roles in cancer progression, metastasis in distant tissues and colony formation in varying way (invasivemetastatic cascades). Cell-cell and cell-matrix interactions of cancer cells with environments determine the metastatic spread (linear or parallel mechanisms) [7]. Alterations in these molecules are observed during tumor progression and metastasis $[40,41]$. Heparin can inhibit
CAM related metastatic processes and improve therapeutic outcomes in patients with solid tumors, especially in lung cancers $[45,46]$.

Primary tumors

(Anti-proliferative agents)

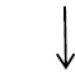

Tumor invasions

(MMP inhibitors)

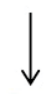

Tumor intravasation

(Antimobility \& cellular signal-related)

(Immune promoters and anticoagulants)

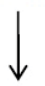

Tumor extravasation

(MMP inhibitors and antimobility agents)

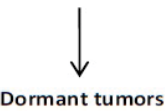

(Unknown)

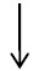

Micrometastatic foci

(Antivacular agents)

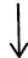

Metastatic colony in distant tissue

(Apoptic agents or others)

Figure 1: Proposed strategy of antimetastatic agents against different stages of invasive-metastatic cascade. 


\section{Cancer stem cell inhibitors}

Cancer stem cell (CSC) is still an enigma for modern biomedical scientists. Its character is very tricky-tumor renewable after operations and drug therapy [28-30]. This tumor renewal itself is closely related to neoplasm metastasis and drug resistance. Presently, CSC is commonly resistance to conventional drug therapy, even anticancer drug combinations. Future therapeutic study, as we can guess, must rely on its biological characters first. Only after fully understanding the biology of CSC, effective therapeutics can be expected.

\section{Cancer plasticity (EMT/MET)}

One of the greatest advances in cancer biological/pathologic study over the past decade is the linkage between EMT/MET and adaptive phenotype of neoplasm tissue $[47,48]$. The therapeutic interventions against tumor plasticity have been carried out widely [31,33]. We hope some effective therapeutic options might be stood out in the following decades.

\section{Sialic acid-related drugs and therapies}

The earliest work tackling the phenomenon of a positive relationship between sias and tumors can be traced back to Kimura et al. from 1958. Their discovery is tumor cells might excrete and contain more sialyl glycoproteins or glycolipids. These characteristics later have been found to be linked with highly metastatic tumor types, organ origin, site preference and targeted therapies [20-22]. Since 1990s, a great number of researches have also showed diagnostic and therapeutic utility patients with tumors of high levels of sialylations. Many patho-therapeutic relationships can be found out and promoted by sialylation changes in clinical cancer diagnostics and treatments. These types of experimental and therapeutic models are reflected in Figure 2 and Table 2.

\section{Combinations of western medicine with TCM in cancer treatments}

Cancer treatment by TCM is one of hot-spots in modern China and even earns growing popularity worldwide. In most cases of cancer treatments, seeking strengthening upright air therapy rather than expelling outside damaging air therapies is proved to be higher utilities and therapeutic outcome improvements [49,50]. Additionally, expelling exogenous wind-heat recipes are also utilized for cancer therapies by TCM.

\section{Other therapeutic targets}

Beside drugs mentioned above, other new types of drug targets are also available worldwide [51-60]. They are cell-signal inhibitors, AMF, HGF/c-Met, TGF- $\beta$ inhibitors, $\beta$-catenin inhibitors [59], cell movement inhibitors [60] and newly discovered targets globally. Most of these metastatic-related targets and inhibitors have not been licensed but have a great potential for future clinical utility. The more these targets are studied, the more useable drugs could be expected.

\section{Targeting the formed metastatic foci in the clinic}

Most people die of cancer with formed metastatic cancer and organ failures. In these patients, MMPs inhibitors or antivascular agents or other therapeutic options usually do not work at all. Given this grim situation, high active drugs targeting to neoplasm metastasis that can greatly control physiological conditions for patients need to be developed.

It might broaden present customs of finding antimetastatic

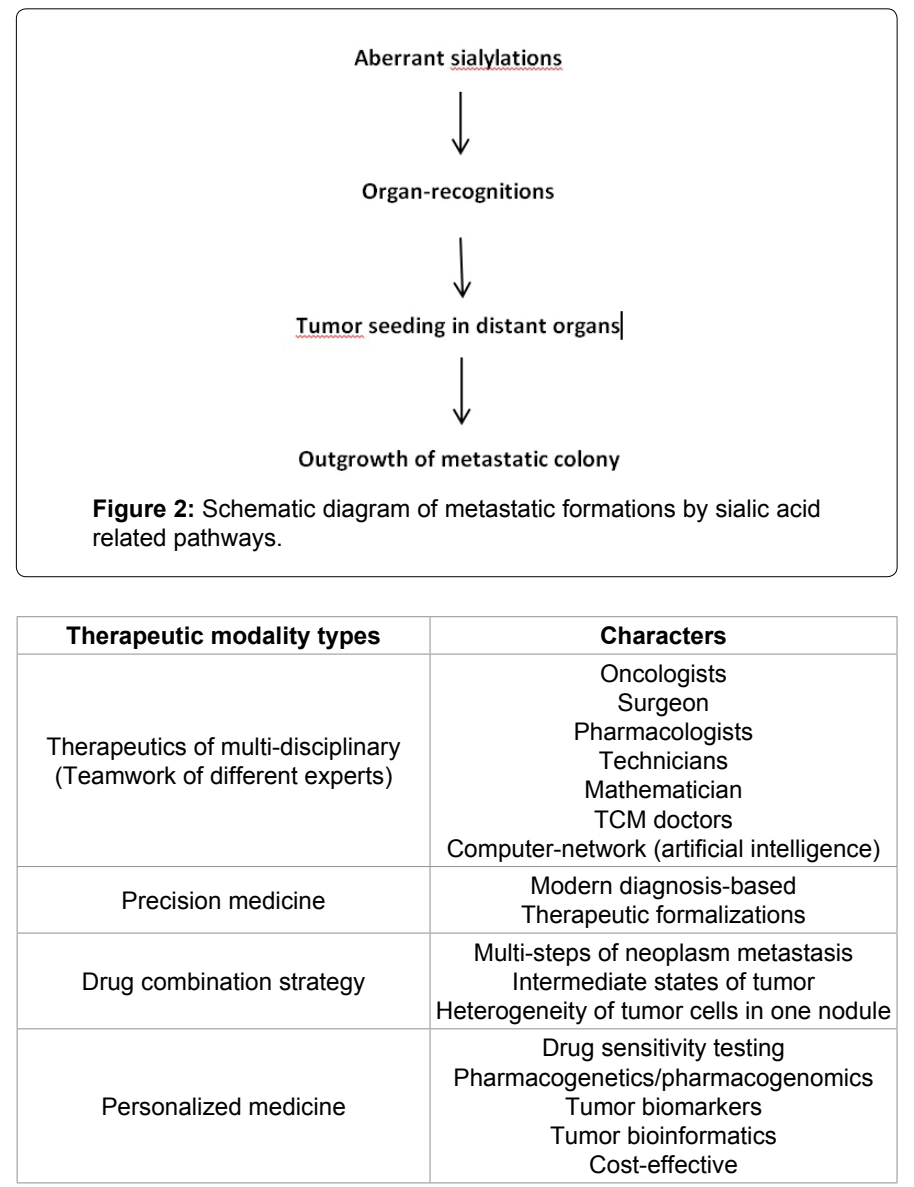

Table 2: Modern therapeutic modality for neoplasm metastases.

drugs only into clinical drug option strategy as a complementary and perfection of individualized cancer therapy/personalized cancer therapy (ICT/PCT) [61-65].

\section{Animal tumor models and anti-metastatic drug developments}

Currently, many compounds that can greatly inhibit tumor metastasis in animal models fail to show any therapeutic benefits in cancer patients clinically. It is probably caused by lack of good animal tumor models for that [33]. As a result, a lot of other good metastatic models must be utilized in anticancer drug evaluations.

\section{Modern Therapeutic Modalities}

Besides the promotion of anticancer drug developments, cancer therapeutic study in the clinic is also important route to improve cancer metastatic medications and managements.

In these items of clinical cancer therapeutic options, drug combinations and personalized medicine deserve further explanations because these two topics are developing rapidly more recently;

\section{Drug combination}

Anticancer drug combinations many times can receive unexpected therapeutic benefits in the clinic. Yet, anticancer drug combination needs to transform from doctor's experience into scientific-based investigations [66]. In our recent study, this kind of scientific research has large things to do $[67,68]$, including experimental study of every possibility and global cooperation among clinical doctors. 
Citation: Lu DY, Lu TR, Xu B, Che JY, Wu SY, et al. (2018) Anti-Metastatic Drug Developments: Work Out towards New Direction. Med Chem (Los Angeles) 8: 192-196. doi: 10.4172/2161-0444.1000512

\section{Future Directions}

\section{Global participations}

Anticancer drug development is entering into bottleneck stage [8-10,69,70]. Currently, anticancer drug development (including antimetastatic drugs) should not solely rely on small number of most advanced countries in medical/pharmaceutical science and technology. Global participation is indispensable.

\section{Conclusion}

Cancer metastasis is the main cause of cancer patient mortality worldwide. We thus need to pay more attentions on these pathotherapeutic relationship researches and enhance our horizon on this matter. As the large population of global cancer patients (approximately 15 million) occur every year, if we adhere and improve in metastatic therapy, we might save life of millions each year. In this regard, let's do it as early as possible.

\section{References}

1. Fojo T (2016) The highest of ignorance in oncology. Seminars in Oncology 43: 623-624.

2. Hanahan $D$, Weinberg RA (2011) The hallmarks of cancer, the next generation Cell 144: 646-674.

3. Mina LA, Sledge GW (2011) Rethinking the metastatic cascade as a therapeutic target. Nat Rev Clin Oncol 8: 325-332.

4. Talmadge JE, Fidler IJ (2010) The biology of cancer metastasis: historical perspective. Cancer Res 70: 5649-5669.

5. Valastyan S, Weinberg RA (2011) Tumor metastasis: molecular insights and evolving paradigms. Cell 147: 275-292.

6. Lu DY, Lu TR, Cao S (2012) Cancer metastases and clinical therapies. Cell Dev Biol 1: e110.

7. Lu DY, Lu TR, Wu HY, Cao S (2013) Cancer Metastasis treatments. Current Drug Therapy 8: 24-29.

8. Ruggeri BA, Camp F, Miknyoczki S (2014) Animal models of disease: Preclinical animal models of cancer and their applications and utility in drug discovery. Biochemical Pharmacology 87: 150-161.

9. Herter-Sprie GS, Kung AL, Wong KK (2013) New cast for a new era: preclinical cancer drug development revisited. J Clin Investigation 123: 3639-3645.

10. Hellmann K, Burrage K (1969) Control of malignant metastases by ICRF-159. Nature 224: 273-275.

11. Herman EH, Witiak DT, Hellmann K, Waradek VS (1982) Properties of ICRF159 and related Bis(dioxopiperazine) compounds. Advances in Pharmacology and Chemotherapy 19: 249-290.

12. Kessenbrock K, Plaks V, Werb Z (2010) Matrix metallopoteinases: regulator of the tumor microenvironment. Cell 141: 52-67.

13. Taraboletti G, Margosio B (2001) Antiangiogenic and antivascular therapy for cancer. Current Opinion in Pharmacology 1: 378-384.

14. Folkman J (2006) Angiogenesis. Annual Rev Med 57: 1-18.

15. Fidler IJ (1985) Macrophages and metastasis-a biological approach to cancer therapy: presidential address. Cancer Res 45: 4714-4726.

16. Lu DY, Xi YC (2012) Antimetastatic therapies according to metastatic cascade. Adv Pharmacoepidemiology \& Drug Safety 1: e107.

17. Thejass P, Kuttan G (2006) Antimetastatic activity of Sulforaphane. Life Science 78: 3043-3050.

18. Lee SJ, Chung IM, Kim MY, Park KD, Park WH, Moon HI (2009) Inhibition of lung metastasis in mice by Oligonol. Phytotherapy Res 23: 1043-1046.

19. Lu DY, Cao JY (2001) Structural aberration of cellular sialic acids and their functions in cancer. J Shanghai Univ (Eng) 5: 164-170.

20. Lu DY, Lu TR, Wu HY (2011) Antimetastatic therapy targeting aberrant sialylation profiles in cancer cells. Drug Therapy Studies 1: e12.
21. Lu DY, Lu TR, Wu HY (2012) Development of antimetastatic drugs by targeting tumor sialic acids. Scientia Pharmaceutica 80: 497-508.

22. Reuben JM, Doyle GV, Allard WJ, Terstappen LW, Hayes DF (2004) Circulating tumor cells, disease progression, and survival in metastatic breast cancer. N Engl J Med 351: 781-791.

23. Fidler IJ (2003) The pathogenesis of cancer metastasis: the "seed and soil" hypothesis revisited. Nature Rev Cancer 3: 453-458.

24. Lu DY, Chen XL, Ding J (2007) Treatment of solid tumors and metastases by fibrinogen-targeted anticancer drug therapy. Medicinal Hypotheses 68: 188193.

25. Bobek V (2012) Anticoagulant and fibrinolytic drugs-possible agents in treatment of lung cancer? Anticancer Agents in Medicinal Chemistry 12: 580 588

26. Rothwell P, Fowkes FG, Belch JF, Ogawa H, Warlow CP, et al. (2011) Effect of daily aspirin on long-term risk of death due to cancer: analysis of individual patient data from randomized trials. Lancet 377: 31-41.

27. Yakisich JS (2012) Challenges and limitations of targeting cancer stem cells and/or the tumor microenvironment. Drug and Therapy Study 2: e10.

28. Park TS, Donnenberg VS, Donnenberg AD, Zambidis ET, Zimmerlin L (2014) Dynamic interactions between cancer stem cells and their stromal partners. Current Pathology Reports 2: 41-52.

29. Magee JA, Piskounova E, Morrison SJ (2012) Cancer stem cells: impact, heterogeneity, and uncertainty. Cancer Cell 21: 283-296.

30. Nieto MA, Huang RY, Jackson RA, Thiery JP (2016) EMT. Cell 166: 21-45.

31. Lu DY, Lu TR, Xu B, Qi RX, Sastry NY, et al. (2016) Cancer metastasis, a clinical dilemma for therapeutics. Current Drug Therapy 11: 163-169.

32. Lambert AW, Pattabiraman DR, Weinberg RA (2017) Emerging biological principles of metastasis. Cell 168: 670-691.

33. Yang G, Li X, Li X, Wang L, Li J, et al. (2012) Traditional Chinese medicine in cancer care: a review of case series published in the Chinese literature. Evid Based Complement Alternate Med.

34. Lu DY, Lu TR (2010) Anticancer activities and mechanisms of bisdioxopiperazine compounds probimane and MST-16. Anti-Cancer Agent Medicinal Chemistry 10: 78-9.

35. Lu DY, Ding J, Chen RT, Xu B, Lu TR (2016) Antimetastatic activities and mechanisms of action among Bisdioxopiperazine compounds. Pharmaceutical Formulation and Medicinal Chemistry: Mechanisms, Developments and Treatments. In: Moore B (ed.), Nova Science Publishing, United States, pp: $73-106$.

36. James SE, Salsbury AJ (1974) Effect of ( \pm )-1,2-bis(3,5-dioxopiperazin-1-yl) propane on tumor blood vessels and its relationship to the antimetastatic effect in the Lewis lung carcinoma. Cancer Res 34: 839-842.

37. Lu DY, Wu FG, Shen ZM, Lu TR, Wu HY, et al. (2010) Different spontaneous pulmonary metastasis inhibitions against Lewis lung carcinoma in mice by bisdioxopiperazine compounds of different treatment schedules. Scientia Pharmaceutica 78: 13-20

38. Lu DY, Chen RT, Lu TR, Wu HY, Qu RX, et al. (2010) The absorption, distributions and excretions of ${ }^{14} \mathrm{C}$-probimane. Scientia Pharmaceutica 78 $445-450$.

39. Dvorak HF (2015) Tumor stroma, tumor blood vessels, and anti-angiogenesis therapy. Cancer J 21: 237-243.

40. Dvorak HF, Weanor VM, Tisty TD, Bergers G (2011) Tumor micro-environment and progression. J Surg Oncol 103: 468-474

41. Klein CA (2008) The metastasis cascade. Science 321: 1785-1787.

42. Lu DY, Xu B, Ding J (2004) Antitumor effects of two bisdioxopiperazines against two experimental lung cancer models in vivo. BMC Pharmacology 4: 32.

43. Lu DY, Huang M, Xu CH, Zhu H, Xu B, et al. (2006) Medicinal chemistry of probimane and MST-16: comparison of anticancer effects between bisdioxopiperazines. Medicinal Chemistry 2: 369-375.

44. Lu DY, Lu TR, Chen XL, Xu B, Ding J (2015) Plasma fibrinogen concentration in patients with solid tumor and therapeutic improvements by combining anticoagulants and fibrinolytical agents. Advances in Pharmacoepidemiology \& Drug Safety 4: e133. 
Citation: Lu DY, Lu TR, Xu B, Che JY, Wu SY, et al. (2018) Anti-Metastatic Drug Developments: Work Out towards New Direction. Med Chem (Los Angeles) 8: 192-196. doi: 10.4172/2161-0444.1000512

45. Lu DY, Lu TR, Chen EH, Ding J, Xu B (2015) Tumor fibrin/fibrinogen matrix as a unique therapeutic target for pulmonary cancer growth and metastases. Clin Res Pulmonology 3: 1027.

46. Thiery JP, Acloque H, Huang RYJ, Nieto MA (2009) Epithelial-mesenchymal transitions in development and disease. Cell 139: 871-890.

47. Kalluri R, Weinberg RA (2009) The basics of epithelial-mesenchymal transition. J Clin Invest 119: 1420-1428.

48. Lu DY (2014) Personalized Cancer Chemotherapy, An Effective Way for Enhancing Outcomes in Clinics. In: Lu DY (eds.) Assistant chemotherapy. Woodhead Publishing, Elsevier, UK, pp: 43-48.

49. Lu DY, Lu TR, Che JY, Wu HY (2014) Old theories revisited on cancer assistant therapy. Int J Medical and Health Sciences Res 1: 50-57.

50. Shu L, Cheung KL, Khor TO, Chen C, Kong AN (2010) Phytochemicals: cancer chemoprevention and suppression of tumor onset and metastasis. Cancer Metastasis Rev 29: 483-502.

51. Vetvicka V, Fusek M (2012) Procathepsin D as a tumor marker, anti-cancer drug or screening agent. Anticancer Agents in Medicinal Chemistry 12: 172 175 .

52. Chen L, Yang S, Jakoncic J, Zhang JJ, Huang XY (2010) Migrastin analogues target fascin to block tumor metastasis. Nature 464: 1062-1066.

53. Valastyan S, Reinhardt F, Benaich N, Calogrias D, Szasz A, et al. (2009) A pleiotropically acting microRNA, miR-31, inhibits breast cancer metastasis. Cell 137: 1032-1046.

54. liizumi M, Liu W, Pai SK, Furuta E, Watabe K (2008) Drug development against metastasis-related genes and pathways: a rationale for cancer therapy. BBA 1786: 87-104.

55. Lu DY, Lu TR, Ding J (2010) Cell biological manifestations of Bisdioxopiperazines: treatment of human tumor cell lines in culture. Anticancer Agents Med Chem 10: 657-660.

56. Goodman SL, Picard M (2012) Integrins as therapeutic targets. Trends Pharmacol Sci 33: 405-412.

57. Paredes J, Figueiredo J, Albergaria A, Oliveira P, Carvalho J, et al. (2012) Epithelial E- and P-cadherinss, role and clinical significance in cancer. BBA 1826; 297-311.
58. Bendas G, Borsig L (2012) Cancer cell adhesion and metastasis, selectins integrins, and the inhibitory potential of heparins. Int J Cell Biology 676731.

59. Lu DY, Lu TR (2010) Antimetastatic activities and mechanisms of bisdioxopiperazine compounds. Anti-Cancer Agent Medicinal Chemistry 10: 564-570.

60. Lu DY, Lu TR, Chen XL, Ding J (2012) Individualized cancer chemotherapy Hypotheses in Clinical Medicine. In: Shoja MM, Agutter PS, Tubbs RS, Ghane M, Ghabili K, et al. (eds.). Nova Science Publisher, United State, pp: 199-216.

61. Lu DY (2014) Personalized cancer chemotherapy, an effective way for enhancing outcomes in clinics. Woodhead Publishing, Elsevier, UK.

62. Lu DY, Lu TR, Wu HY (2014) Personalized cancer therapy, a perspective. Clinical Experimental Pharmacology 4: 153.

63. Lu DY, Lu TR, Che JY, Wu HY (2014) Individualized cancer therapy. Innovations in Pharmaceuticals and Pharmacotherapy 2: 458-69.

64. Lu DY, Lu TR, Che JY, Yarla NS (2018) Individualized cancer therapy, what is the next generation? EC Cancer 2: 286-297.

65. Lu DY (2014) Personalized Cancer Chemotherapy, An Effective Way for Enhancing Outcomes in Clinics. In: Lu DY (eds.) Drug combinations. Woodhead Publishing, Elsevier, UK, pp: 37-42.

66. Lu DY, Chen EH, Wu HY, Lu TR, Xu B, et al. (2017) Anticancer drug combination, how far we can go through? Anticancer Agents Med Chem 17: 21-28.

67. Lu DY, Lu TR, Yarla NS, Wu HY, Xu B, et al. (2017) Drug combination in clinical cancer treatment. Reviews on Recent Clinical Trials 12: 202-211.

68. Lu DY, Lu TR, Zhu H, Ding J, Xu B, et al. (2017) Anticancer drug development, getting out from bottleneck. Int J Mol Biol 2: 00010.

69. Lu DY, Lu TR, Yarla NS, Xu B, Chen EH, et al. (2017) Anticancer drug development, breakthroughs are waiting. Adv Pharmacology \& Clinical Trials 2: 119.

70. Lu DY, Lu TR, Chen EH, Xu B, Yarla NS, et al. (2017) Anticancer drug development, system updating and global participation. Current Drug Therapy 12: $37-45$. 